\title{
USO DE REALIDADE AUMENTADA NA EDUCAÇÃO PATRIMONIAL
}

\author{
DARIO. CAROLINA \\ Mestranda em Arquitetura e Urbanismo \\ Faculdade Meridional - IMED \\ Rio Grande do Sul; Brasil \\ carol.dario@hotmail.com
}

\author{
SILVA. THAÍSA LEAL DA \\ Doutora em Engenharia Eletrotécnica e de Computadores \\ Faculdade Meridional - IMED \\ Rio Grande do Sul; Brasil \\ thaisa.silva@imed.edu.br
}

\begin{abstract}
RESUMO
$\mathrm{O}$ avanço das novas tecnologias tem possibilitado um maior acesso tanto à educação quanto à cultura de forma acelerada. Essas tecnologias transformam-se em ferramentas para o desenvolvimento da educação patrimonial, auxiliando no amadurecimento da compreensão, da valorização e preservação do patrimônio cultural. $\mathrm{O}$ conceito de patrimônio abrange bens materiais e imateriais, que possuem valor significativo para uma determinada região e/ou população. Quando um local com particularidades históricas é visitado por meio de realidade virtual, o mesmo pode provocar a imaginação do visitante, permitindo-o experenciar um momento que nunca viveu. Neste cenário, a utilização de plataformas de realidade virtual e aumentada tem tido um significativo crescimento, pois promove a interação dos usuários com as perspectivas do mundo real, fazendo com que os mesmos sintam-se imersos dentro de determinados ambientes. A utilização dessas tecnologias no ensino patrimonial permite a visualização de locais que podem estar em estado de ruínas ou até mesmo em risco estrutural, possibilitando a melhor compreensão da importância da manutenção, restauração e preservação dos patrimônios culturais. Assim, esse trabalho pretende analisar como o uso de realidade virtual e aumentada pode promover a educação patrimonial. Para tanto, a será desenvolvida uma revisão bibliográfica, onde serão investigadas as aplicações dessas tecnologias em diferentes contextos. Como resultado será apresentada uma análise de trabalhos relacionados a aplicação de realidade aumentada e virtual em patrimônios históricos apontando algumas vantagens e/ou desvantagens do uso dessas tecnologias.
\end{abstract}

Palavras-chave: patrimônio; educação patrimonial; realidade aumentada; realidade virtual.

\begin{abstract}
The advancement of new technologies has enabled greater access to both education and culture at an accelerated rate. These technologies become tools for the development of heritage education, helping to mature understanding, appreciation and preservation of cultural heritage. The concept of heritage encompasses material and immaterial goods that have significant value for a particular region and / or population. When a place with historical particularities is visited through virtual reality, it can provoke the visitor's imagination, allowing him to experience a moment that never lived. In this scenario, the use of virtual and augmented reality platforms has had a significant growth, as it promotes user interaction with real world perspectives, making them feel immersed within certain environments. The use of these technologies in heritage education allows the visualization of sites that may be in ruins or even in structural risk, allowing a better understanding of the importance of maintaining, restoring and preserving cultural heritage. Thus, this paper aims to analyze how the use of virtual and augmented reality can promote heritage education. To this end, a literature review will be developed, where the applications of these technologies in different contexts will be investigated. As a result, will be presented an analysis of works related to the application of augmented and virtual reality in historical heritage pointing some advantages and / or disadvantages of the use of these technologies.
\end{abstract}

Keywords: heritage; heritage education; augmented reality; virtual reality. 


\section{USO DE REALIDADE VIRTUAL E AUMENTADA NA EDUCAÇÃO PATRIMONIAL}

\section{INTRODUÇÃO}

A magnitude dos Patrimônios Históricos e Culturais se baseia na importância que os mesmos possuem para a comunidade, a preservação da memória, e seu simbolismo local. Desta forma, resguardar estes bens é conservar viva a história, a qual se faz relevante para a valorização da individualidade histórica do patrimônio, e consequentemente na concepção do envolvimento da comunidade na qual está inserido, estimulando a atenção em relação ao bem e a história que o mesmo resguarda.

Em meio as mudanças globais, a tecnologia assume uma função de liderança na revolução social, ora pela agilidade das informações, ora no rompimento de limites entre países, indivíduos e instituições. Deste modo, a tecnologia tem influência direta sobre a educação, a qual teve de ser repensada no interior e no exterior das salas de aula, de maneira a seguir as transformações tecnológicas e introduzir gradativamente o uso de tecnologias na metodologia de ensinoaprendizagem.

Segundo o Artigo 205 da Constituição Federal (BRASIL,1988), "A educação, direito de todos e dever do Estado e da família, será promovida e incentivada com a colaboração da sociedade, visando o pleno desenvolvimento da pessoa, seu preparo para o exercício da cidadania e sua qualificação para o trabalho". Sendo assim, torna-se uma ferramenta fundamental para a evolução do indivíduo, e para sua inclusão no cenário social, econômico e histórico, instigando o mesmo a desenvolver o sentimento de pertencimento a estes ambientes, a sua história e cultura. Nesse contexto, a educação patrimonial é um componente importante que consiste num "processo permanente e sistemático de trabalho educacional centrado no Patrimônio Cultural como fonte de conhecimento e enriquecimento individual e coletivo" (HORTA, GRUNBERG e MONTEIRO, 1999, p. 6).

Através deste trabalho pretende-se demonstrar a relevância da educação patrimonial, utilizando-se ferramentas tecnológicas para auxiliar neste processo de reconhecimento dos bens culturais como parte da história e da cultura de determinado local, despertando o sentimento de pertencimento, e desta forma cooperando para estimular a compreensão histórico-cultural coletiva. A temática de Educação Patrimonial torna-se cada vez mais relevante devido a crescente expansão da tecnologia, onde a história cultural vem perdendo força, é preciso aliar esses dois setores, tirando vantagem do uso da tecnologia em favor dos bens históricos culturais.

\section{O USO DE TECNOLOGIA NA EDUCAÇÃO PATRIMONIAL}

Conforme afirma Oliveira (2008), a educação patrimonial é um método pelo qual os indivíduos compreendem a dimensão e a relevância da manutenção e preservação de patrimônios culturais, desse modo se apropriam destes bens, percebendo que estes representam a identidade da comunidade e das pessoas que ali pertencem. Segundo o Artigo 216 da Constituição Federal, fazem parte dos patrimônios Brasileiros:

Constituem patrimônio cultural brasileiro os bens de natureza material e imaterial, tomados individualmente ou em conjunto, portadores de referência à identidade, à ação, à memória dos diferentes grupos formadores da sociedade brasileira, nos quais se incluem: I - as formas de expressão; II - os modos de criar, fazer e viver; as criações científicas, artísticas e tecnológicas; IV - as obras, objetos, documentos, edificações e demais espaços destinados às manifestações artístico-culturais; V - os conjuntos urbanos e sítios de valor histórico, paisagístico, artístico, arqueológico, paleontológico, ecológico e científico. Parágrafo $1^{\circ}$ - $\mathrm{O}$ Poder Público, com a colaboração da comunidade, promoverá e protegerá o patrimônio cultural brasileiro, por meio de inventários, registros, vigilância, tombamento e desapropriação e de outras formas de acautelamento e preservação. Parágrafo $4^{\circ}$-Os danos e ameaças ao patrimônio cultural serão punidos, na forma da lei (BRASIL, 1988, p. 35).

Conforme Horta, Grunberg e Monteiro (1999), a educação patrimonial é um processo de "alfabetização cultural” o qual oportuniza aos indivíduos o entendimento do ambiente sociocultural e histórico em que estão introduzidos. Desta forma, ao se reconhecer pertencendo àquele espaço se torna um motivador de práticas referentes a preservação patrimonial, a qual se faz importante visto que mantém viva a memória contida nos patrimônios históricos e culturais. Posto isso, Tolentino (2012) aponta que a participação dos diversos setores sociais na concepção e preservação do que se entende como sendo patrimônio histórico, se deve pela vasta aplicação da educação patrimonial.

O termo educação patrimonial surgiu no Brasil a partir de 1937, após a criação do Instituto do Patrimônio Histórico e Artístico Nacional - IPHAN, o qual é encarregado pela elaboração das leis, e pela difusão das políticas referentes a preservação e manutenção dos patrimônios históricos. Os primeiros atos educativos sobre os bens culturais inicialmente eram específicos para museus e foram aplicados em 1967, neste período foram preconizados os tombamentos voltados aos bens materiais. Em consequência disso, foram criados encontros nacionais com a presença de professores, de modo 
a conduzir uma relação entre a educação e a cultura. Desta forma, o conceito de patrimônio cultural e histórico foi se alargando até abranger os bens imateriais e toda herança cultural do país. Com essa expansão do conceito, surge em 2004, a Gerência de Educação Patrimonial e Projetos - GEDUC, a qual foi criada a fim de gerenciar a educação patrimonial. (FLORENCIO et al, 2014)

Observa-se que o tema de educação patrimonial aliado ao uso de tecnologias ainda é pouco abordado, durante a pesquisa bibliográfica para desenvolvimento deste artigo foram encontrados poucos trabalhos relacionados a esse tema. Observa-se a utilização de novas tecnologias no processo de ensino da educação patrimonial, entretanto ainda é perceptível a necessidade de se evoluir quanto ao uso dessas tecnologias, utilizando as mesmas num âmbito mais interdisciplinar. As novas possibilidades tecnológicas viabilizam uma transição entre o método tradicional da prática educativa, a qual foca na aula expositiva apenas utilizando livros, para um panorama digital, onde alunos e professores fazem uso de computadores, tablets e demais equipamentos eletrônicos.

Segundo Tardivo (2014) no Brasil ainda se encontram algumas dificuldades para essa inserção, pois há uma carência de informações e treinamentos para os professores, da mesma forma que falta infraestrutura e equipamentos modernos que atendam esta demanda. Conforme mostra a pesquisa realizada pelo Instituto Ayrton Senna (REF), "apenas 53\% das escolas públicas do país têm acesso à internet e só $43 \%$ dispõem de banda larga. Na rede privada, a proporção de estabelecimentos com banda larga chega a 80\%" (O GLOBO, 2016).

Nessa perspectiva, nota-se a presença da implantação dessas tecnologias tanto na escola pública, quanto na escola privada, porém é notável a diferença do nível de aplicação e qualidade entre elas. Segundo o relatório anual de Pesquisa Sobre o Uso das Tecnologias de Informação e Comunicação nas Escolas Brasileiras de 2018 (TIC EDUCAÇÃO, 2018) "a ausência de competências para uso das tecnologias pode ser um dos motivos para o baixo percentual de docentes que fizeram uso dos recursos em atividades pedagógicas com os alunos".

\subsection{DEFINIÇÃO DE REALIDADE VIRTUAL E AUMENTADA}

O surgimento dos primeiros simuladores virtuais deu-se em meados de 1910, voltados para a área da aviação, de modo que os pilotos conseguissem praticar de maneira segura e rápida. Após o sucesso da utilização dessa tecnologia, em 1950 foi aplicado no entretenimento através do "Sensorama" que consistia em uma viagem de bicicleta por um bairro nobre da Califórnia, além do campo visual foram adicionados elementos para instigar o olfato do usuário e uma vibração que reproduzia o solavanco do passeio. Desde então o uso da tecnologia vem sendo melhorada e aplicada em diversos contextos (GOUVEIA, 1999).

Se tratando de uma plataforma de simulação do espaço real, o trabalho de aplicação é muito minucioso pois deve representar o mundo real, isso foi alcançado através do procedimento de Realidade Virtual - RV, entretanto a aplicação desse sistema ainda é deficitário, pois sofre influência direta de outros fatores externos como a potência do computador, a tecnologia empregada e até mesmo a agilidade da internet.

Esses métodos são compostos normalmente por um display o qual possibilita a visualização do conteúdo, por um sistema de rastreamento que localiza o ponto exato da aplicação, e por um computador que é responsável por executar os algoritmos do sistema. Nesse sentido, foram desenvolvidos aplicativos mais acessíveis para o público em forma de sensores ópticos, câmeras digitais e GPS. Essa interação entre sistema e usuário acontece pelo uso de cena 3D, a qual não limita os movimentos naturais proporcionando uma maior interação.

Kirner (2008, p. 1-11) define Realidade Aumentada (RA) como "A inserção de objetos virtuais no ambiente físico, mostrada ao usuário, em tempo real, com o apoio de algum dispositivo tecnológico, usando a interface do ambiente real, adaptada para visualizar e manipular os objetos virtuais". Na figura 1 podemos analisar as diferenças entre essas tecnologias:

Figura 1: Diferença entre Realidade Virtual e Realidade Aumentada.

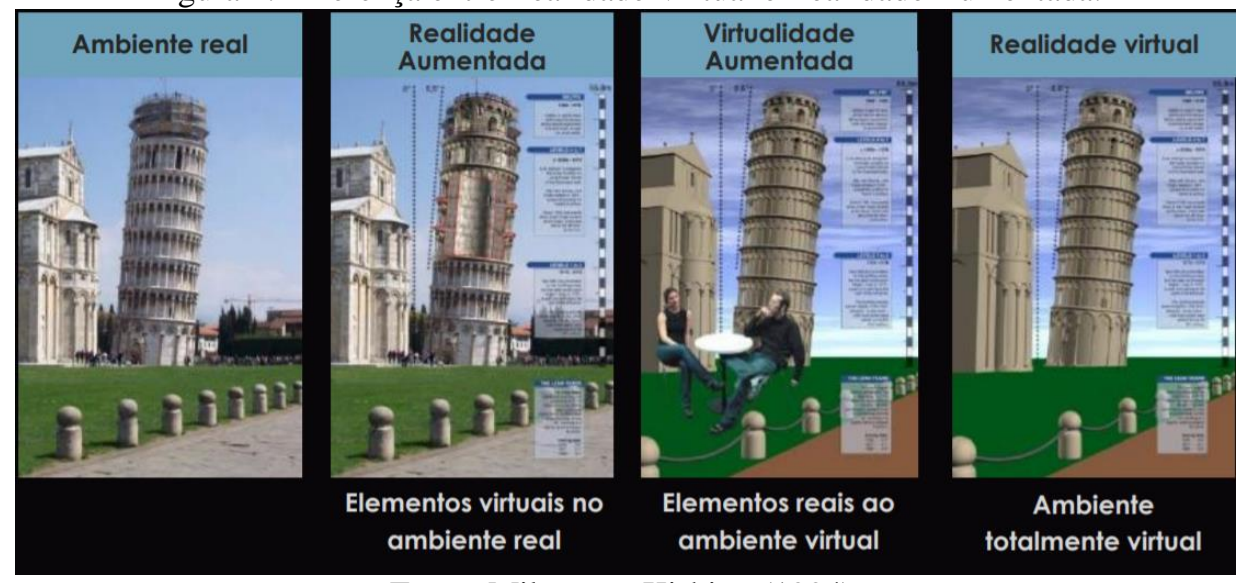

Fonte: Milgram e Kishino (1994). 
As técnicas RA e RV vem tornando-se muito utilizadas na elaboração de maquetes eletrônicas para arquitetos e também designers, já que estas permitem a ampla visualização e interatividade do cliente com o ambiente. RA também é amplamente utilizada para reformas e ampliações, onde já há edificações, assim o usuário/cliente poderá visualizar virtualmente como ficaria a possível reforma, através da sobreposição do ambiente real e o virtual.

Para a aplicação da RA nos bens patrimoniais, essa ferramenta apresenta grande potencialidade, no que diz respeito a educação patrimonial é capaz de criar sobreposições nas edificações patrimoniais, como em ruínas, por exemplo. Com o uso de RA é possível visualizar a forma original reconstituída da edificação, como podemos observar na Figura 2.

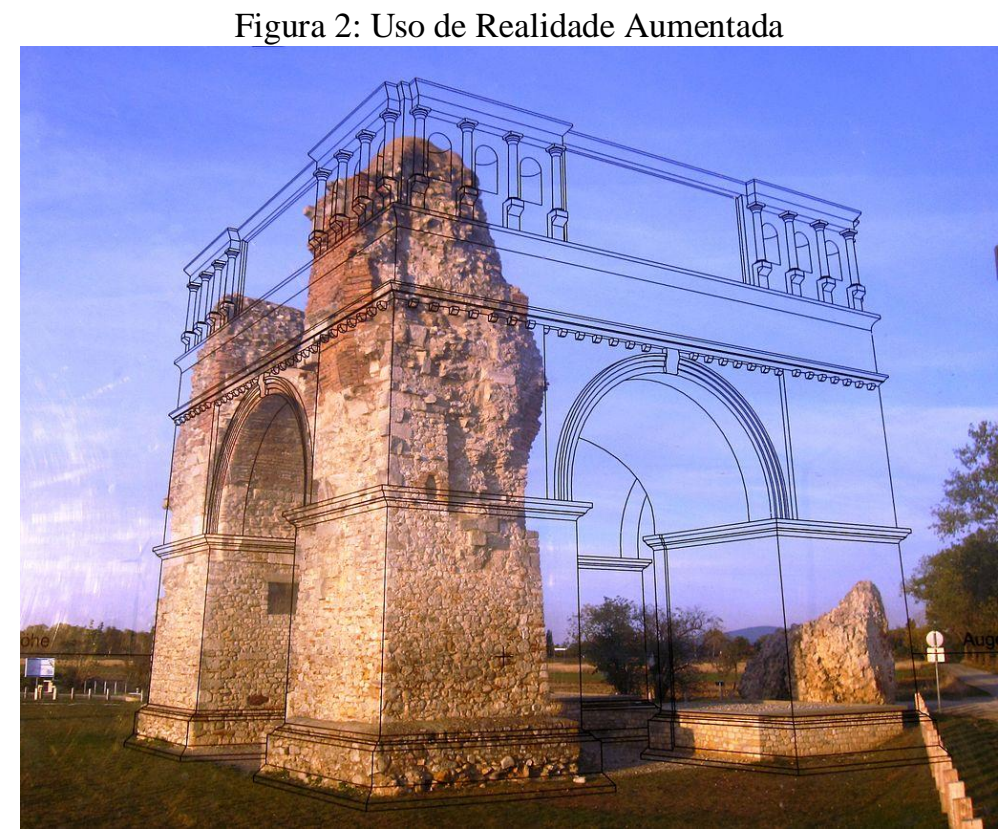

Fonte: Pinterest, 2016

\subsection{APLICAÇÕES DAS TECNOLOGIAS DE RA E RV EM DIFERENTES CONTEXTOS}

Conforme Zuffo et al. (2009, p.2) "nos últimos 50 anos, várias tecnologias de simulação e visualização têm sido desenvolvidas propiciando a criação de ambientes imersivos e semi-imersivos. O conjunto de metodologias e tecnologias para a criação de ambientes interativos totalmente imersivos dominam a Realidade virtual". Essa tecnologia tem apresentado diversas e graduais aplicações em inúmeras áreas de conhecimento, como simulações de vôos e direção, na área da saúde, nos jogos e entretenimentos, nas teleconferências, no ensino e também em ambientes arquitetônicos.

Uma das mais bem-sucedidas aplicações de Realidade Aumentada no âmbito do património cultural foi desenvolvido pelo Museu Powerhouse em Sydney. Explorando a presença maciça do Museu na Câmara dos Comuns, Rob Manson e Alex Young desenvolveram uma aplicação que carrega mais de 400 imagens históricas de Sydney como POIs (Pontos de Interesse), da ciência e da conservação do Património Cultural, e que aparecem quando uma câmera intercepta um marcador. Desta forma, ao andar pelas ruas de Sydney e apontar a câmera do seu dispositivo em um determinado ponto, é possível ver imagens reais do local como foi anos antes, recebendo informações diretamente de um aplicativo ou do arquivo da foto do museu.

A implementação dessas novas tecnologias no ramo de preservação e manutenção do patrimônio histórico, tem representado experiências positivas em diferentes países de modo eficaz e com baixo custo de implantação. Essas tecnologias propiciam novas oportunidades de construir e compartihar conhecimento e estimulam outras possibilidades de relação com o bem material. A realidade aumentada revela-se totalmente adequada de maneira a ampliar a base técnica para intervenções em patrimônios históricos, organizando-os dentro de um sistema virtual. Através desta interação dos indivíduos com o ambiente virtual, cria-se uma relação de respeito e cuidado à medida que reconhecem seu valor e a importância da preservação.

Na Figura 3 podemos apreciar o "Quarteirão dos Trapiches", em que foi aplicada realidade aumentada. Para isso o mesmo foi modelado e suas fachadas brevemente tratadas, e através de um marcador pode ser visualizada, com interação em tempo real pelo software e visualizado pelo computador ou celular. 
Figura 3 - Modelo 3D Quarteirão dos Trapiches

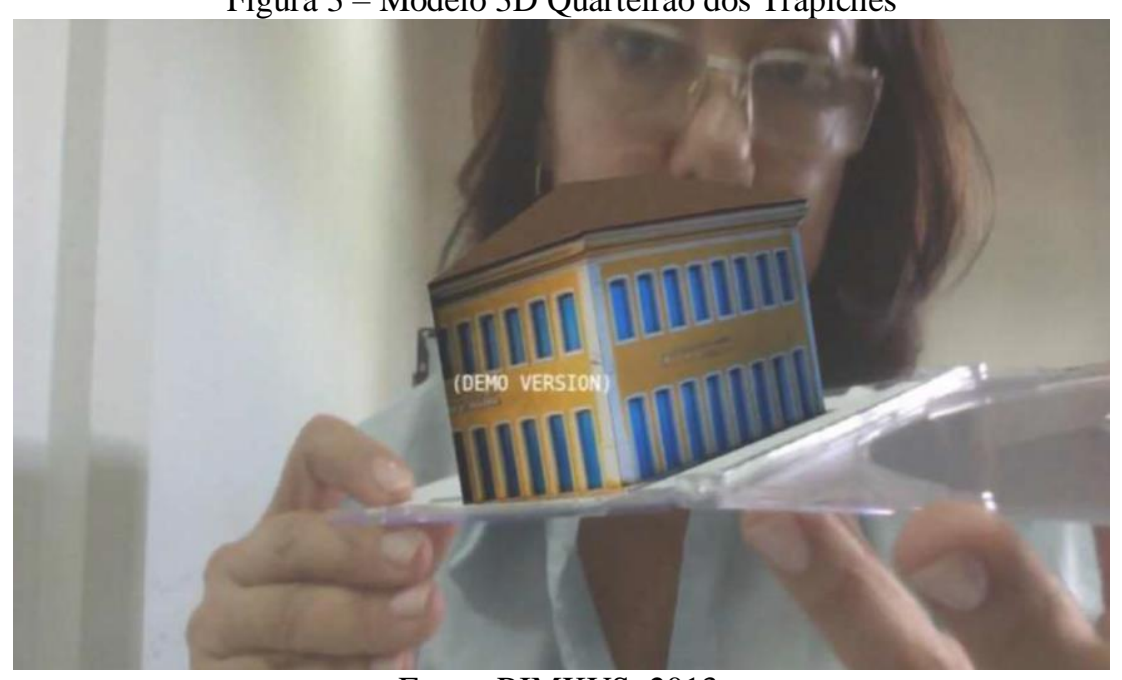

Fonte: RIMKUS, 2013.

Outra interessante aplicação de RA que se pode mencionar, é o projeto ARTHUR - Augmented Round Table for Achitecture and Urbanism Planning (Figura 4), este projeto foi desenvolvido por técnicos e arquitetos na Europa, com o foco em Projetos de Arquitetura e Urbanismo. O objetivo desde aplicativo é preencher a lacuna entre os mundos real e virtual, aprimorando o ambiente de trabalho atual dos usuários com objetos 3D virtuais. O desenvolvimento se concentra em fornecer um ambiente intuitivo, que suporta a interação natural com objetos virtuais, mantendo os mecanismos de comunicação e interação existentes.

Figura 4 - Visualização com display de realidade aumentada

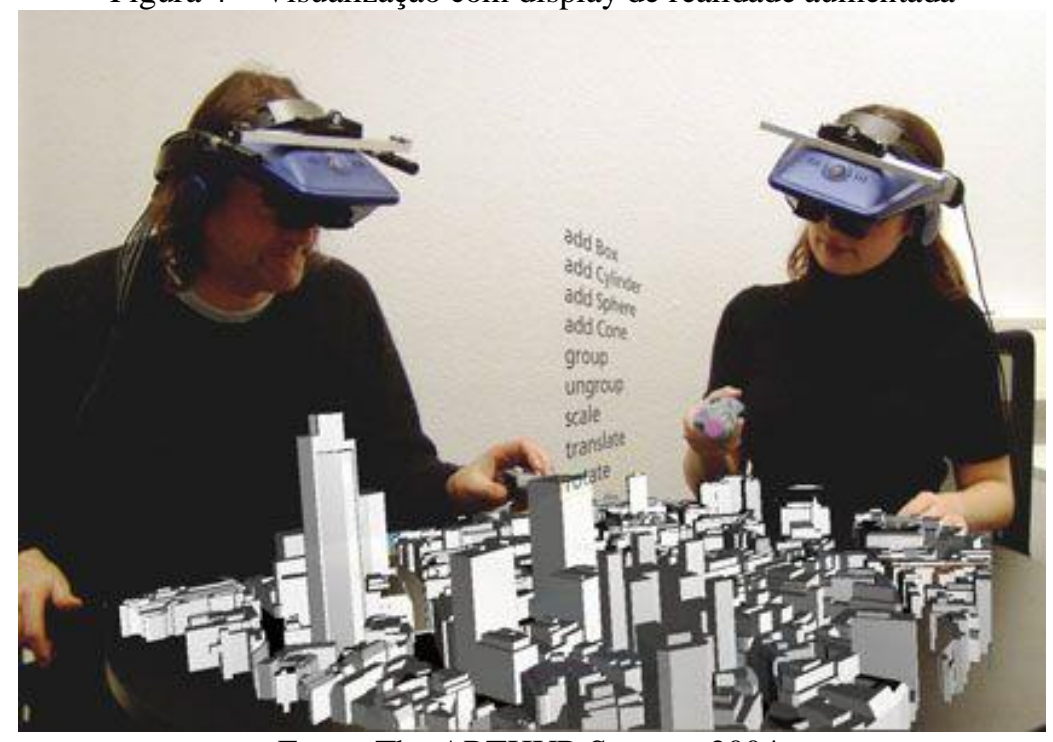

Fonte: The ARTHUR System, 2004.

\subsection{ALGUMAS EXPERIÊNCIAS EM PATRIMÔNIOS HISTÓRICOS}

Quando voltamos o olhar para a aplicação dessas ferramentas no contexto educacional, se trabalha com diversos grupos sociais, que vivem na mesma comunidade, buscando a motivação de ações defensoras da preservação da memória através da tomada de consciência sobre a relevância das gerações, valorizando e resguardando bens patrimoniais. (MACHADO 2004) As realidades virtual e aumentada, podem ser aplicadas na área de educação patrimonial, através da visualização e interação do individuo com o patrimônio cultural, seja em áreas externas como sitios arqueológicos/históricos, seja em áreas internas como museus, oportunizando aos individuos um contato com o bem cultural, e assim instigando a preservação e salvaguarda do patrimônio. Nas subseções a seguir serão apresentados exemplos do uso de técnicas de RA e RV em patrimônios históricos e culturais. 


\subsubsection{Archeoguide: An Augmented Reality Guide for Archaeological Sites}

Archeoguide é um método aplicado através de dispositivos móveis que efetuam a coleta, e fazem o tratamento, armazenamento e disseminação dos dados pertencentes a patrimônios históricos. Para essa aplicação foi selecionado o sitio arqueológico de Olímpia, na Grécia, devido a sua importância para a arquitetura mundial, sendo o local onde ocorriam os jogos olímpicos nos velhos tempos.

Figura 5 - Templo de Hera, em Olímpia: (a) estado atual; (b) Visão virtual do original
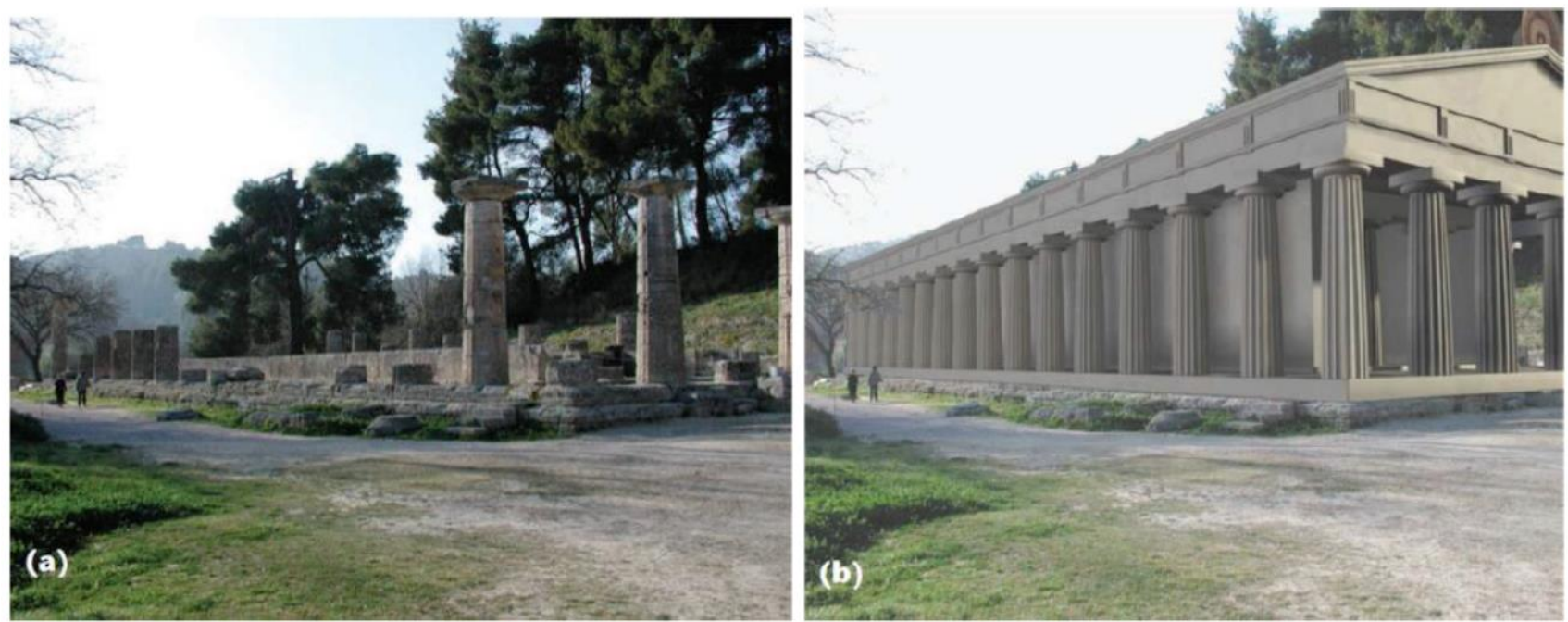

Fonte: VLAHAKIS et al., 2002.

\subsubsection{Digital Yuanmingyuan}

Digital Yuanmingyuan é um sistema de realidade aumentada que usa câmeras de vídeo que são acopladas em monitores de LCD (usados para visualização das imagens). O sítio de Yuanmingyuan foi escolhido por conter mais informações arquitetônicas e registros das construções originais. O jardim real foi construído por seis imperadores da dinastia Qing, e ficou reconhecido como "o jardim de todos os jardins". Tristemente foi destruído por volta de 1840, restando apenas suas ruínas. Com a utilização de realidade aumentada os visitantes podem ver o edificio original se sobrepondo as atuais ruínas. Na Figura 6 é possível ver a aplicação desse sistema.

Figura 6 - Aplicação do sistema em RA: (a) sitio atual em ruínas; (b) visualização em RA

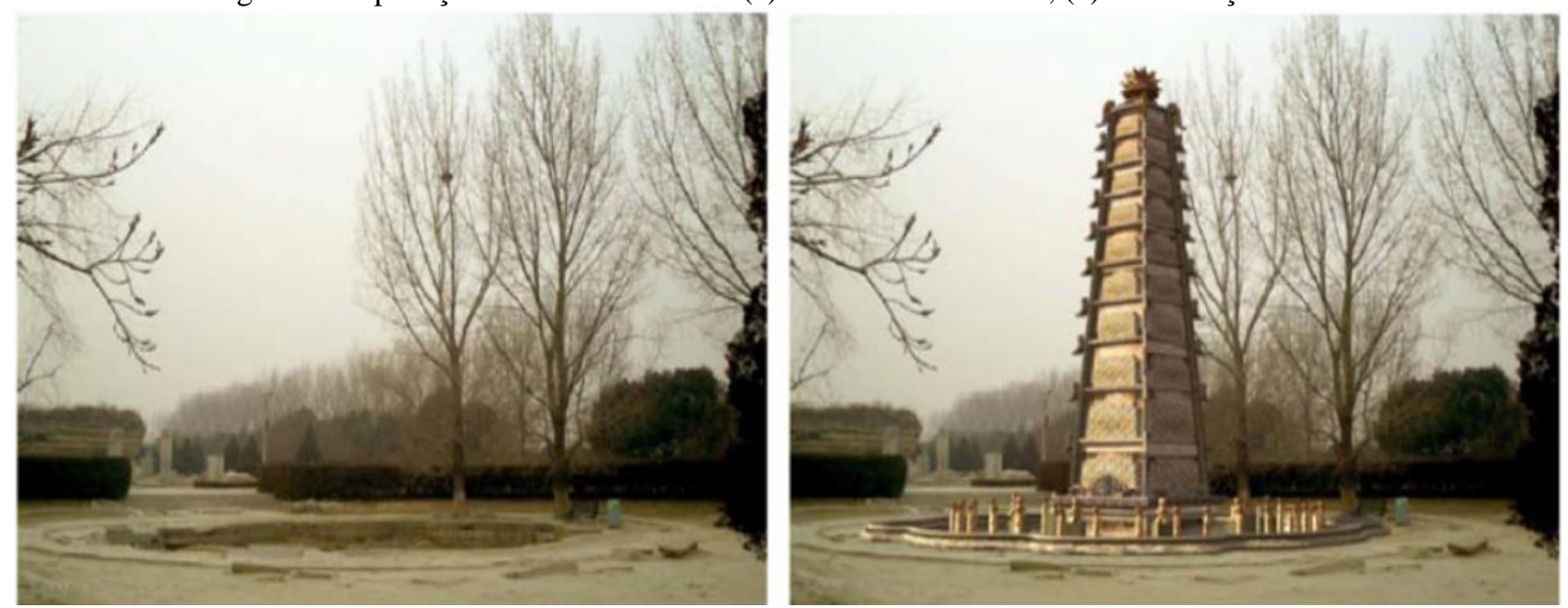

Fonte: WENG, 2011.

A seguir serão apresentadas as considerações finais deste artigo. 


\section{CONSIDERAÇÕES FINAIS}

Após uma pesquisa sobre o tema educação patrimonial e os conceitos que definem patrimônio histórico e cultural, é notável a alta relevância sobre esse instrumento, para um avanço na sociedade, de um sentimento de pertencimento, e como consequência o desenvolvimento na prática de salvaguarda e valorização dos patrimônios históricos e culturais. É relevante destacar que os individuos necessitam de uma maior interação com o bem cultural, e não somente uma exposição didática sobre o referido bem, pois é somente através desse envolvimento que surge a percepção da importância dessa manutenção.

A partir disso, com base nas técnicas apresentadas, foi possível observar o grande potencial da aplicação das Realidades Virtual e Aumentada na educação patrimonial e na divulgação do patrimônio histórico e cultural. Além disso, foi possível verificar que ainda há uma lacuna na inserção dessas ferramentas nas instituições de ensino, porém no que diz respeito a qualidade dessas ferramentas, as mesmas cumprem com eficiência que lhes é proposta. Desta forma, as reconstituições digitais, apresentam novas e extensas possibilidades de visualização e relação com a mémória do local, colaborando para uma maior compreensão e fortalecimento dos bens culturais.

\section{REFERÊNCIAS}

APPLICATIONS. In: Optik - International Journal for Light and Electron Optics. 2011. Disponível em: https://www.researchgate.net/publication/251490721_Display_systems_and_registration_methods_for_augmented_real ity_applications. Acesso em: Dez 2019.

COLIZZI, Lucio; MARTINI, Andrea; CHIONNA, Francesco. (2010). Augmented Reality Applied to the Diagnostics and Fruition of Cultural Heritage. Conservation Science in Cultural Heritage : Historical Technical Journal. 10. 10.6092/issn.1973-9494/2325.

CONSTITUIÇÃO DA REPÚBLICA FEDERATIVA DO BRASI, Edição da Assembléia Legislativa do Estado do Rio Grande do Sul: Brasília, 1988.

DE SOUZA, Ana Clara et al. REALIDADE AUMENTADA APLICADA NA RECONSTITUIÇÃO DE

MOMENTOS HISTÓRICOS. Anais do Encontro Virtual de Documentação em Software Livre e Congresso Internacional de Linguagem e Tecnologia Online, v. 8, n. 1, dez. 2019. ISSN 2317-0239. Disponível em: http://www.periodicos.letras.ufmg.br/index.php/anais_linguagem_tecnologia/article/view/16212. Acesso em: $11 \mathrm{dez}$. 2019.

FLORÊNCIO, Sônia Rampim et al. Educação Patrimonial: histórico, conceitos e processos. Brasília: Iphan, 2014.

GARRIDO R.M., JIMÉNEZ D.V., BALDIRIS S., FABREGAT R. (2015) "Social Heritage" Augmented Reality

Application to Heritage Education. In: De Paolis L., Mongelli A. (eds) Augmented and Virtual Reality. AVR 2015. Lecture Notes in Computer Science, vol 9254. Springer, Cham

GOUVEIA, Luís Manuel Borges. Realidade virtual: Introdução e conceitos associados. UFP. 1999. Disponível em: http://homepage.ufp.pt/lmbg/textos/vr_intro.pdf. Acesso em: 10 dez. 2019.

HORTA, Maria de Lourdes P. GRUNBERG, Evelina. MONTEIRO, Adriane Queiroz. Guia Básico de Educação Patrimonial. Brasília: Instituto do Patrimônio Histórico e

Artístico Nacional, Museu Imperial. 1999.

IPHAN. 2014. Disponível em: http://portal.iphan.gov.br/pagina/detalhes/872. Acesso em: 11 dez. 2019.

KIRNER, C. (2008) "Evolução da Realidade Virtual no Brasil”". In: X Symposium on Virtual and Augmented Reality, João Pessoa, PB, SBC, p. 1-11. Acesso em Março 2011, Disponível em: http://www.ckirner.com/historiarv/historiarv.htm

MACHADO, Maria Beatriz Pinheiro. Educação patrimonial: orientação para professores do Ensino Fundamental e Médio. Caxias do Sul: Maneco, 2004.

MILGRAN, P.; KISHINO, F. A Taxonomy of Mixed Reality Visual Displays. In: EICE Transactions on Information Systems. p. 1321-1329, 1994. 
MOESLUND, Thomas; ORRING, M.; WOLFGANG, Broll; AISH, F.; LIU, Y.; GRANUM, Erik. The ARTHUR System: An Augmented Round Table. CiteSeer, [s. l.], 25 maio 2004. Disponível em: https://www.researchgate.net/publication/2944704_The_ARTHUR_System_An_Augmented_Round_Table. Acesso em: 12 dez. 2019.

MOREIRA, Lorena; LEÃO DE AMORIM, Arivaldo. Realidade Aumentada E Patrimônio Cultural: Apresentação, Tecnologias E Aplicações. Anais do II Seminário Nacional de Documentação do Patrimônio Arquitetônico com o uso de Tecnologias Digitais, v. I, 2012. Disponível em:

https://www.researchgate.net/publication/275153985_REALIDADE_AUMENTADA_E_PATRIMONIO_CULTURAL _APRESENTACAO_TECNOLOGIAS_E_APLICACOES. Acesso em: $11 \mathrm{dez} .2019$.

OLIVEIRA, M. M. A Documentação como Ferramenta de Preservação da Memória: Cadastro, Fotografia, Fotogrametria e Arqueologia. Brasília: IPHAN / Programa Monumenta, 2008.

O GLOBO; $43 \%$ das escolas públicas têm banda larga, contra $80 \%$ das privadas, 2016. Disponível em: http://g1.globo.com/educacao/noticia/2016/01/43-das-escolas-publicas-tem-banda-larga-contra-80-das-privadas.html. Acesso em: 15 dez. 2019.

RIMKUS, Carla Maria Furuno. Avaliação da aplicabilidade da tecnologia da realidade aumentada na área do patrimônio arquitetônico. GEINTEC, São Cristóvão/SE, v. 3, n. 2, p. 70-80, 2013.

SILVA, Ivanilde da Conceição; SILVA, Luciana Mendonça da; FERNANDES, Natália de Andrade; JUNIOR, João Batista Bottentuit; CARVALHO, Conceição de Maria Belfort. Reflexões Sobre a Utilização das Tecnologias no Processo de Ensino- Aprendizagem da Educação Patrimonial no Brasil. Revista Tecnologias na Educação UFMA: II Simpósio Nacional de Tecnologias Digitais na Educação (II-SNTDE), v. 22, ed. Temática VI, 2017. Disponível em: http://tecedu.pro.br/wp-content/uploads/2017/10/Art5-vol.22-Edi\%C3\%A7\%C3\%A3o-Tem\%C3\%A1tica-VI-Outubro2017.pdf. Acesso em: 10 dez. 2019.

SZLACHTA JUNIOR, Arnaldo Martin; RAMOS, Márcia Elisa Teté. POSSIBILIDADES PARA A EDUCAÇÃO PATRIMONIAL POR MEIO DE GAMES DE REALIDADE AUMENTADA. Métis: História \& Cultura, v. 18, ed. 35, 2019. Disponível em: http://www.ucs.br/etc/revistas/index.php/metis/article/view/7799. Acesso em: 12 dez. 2019.

TARDIVO, Jéssica Aline. Ensino, memória e mídias virtuais: os passeios virtuais como possibilidade educacional de resgate da memória de bens culturais sob a ótica de professores de artes do ensino público. Araraquara, 2014.168 p. Dissertação (Mestrado em Educação Escolar). Universidade Estadual Paulista.

TIC EDUCAÇÃO: Comitê Gestor da Internet no Brasil. In: Pesquisa Sobre o Uso das Tecnologias de Informação e Comunicação nas Escolas Brasileiras. Grappa Marketing Editorial, 2018. Disponível em:

https://cgi.br/media/docs/publicacoes/216410120191105/tic_edu_2018_livro_eletronico.pdf. Acesso em: 13 dez. 2019.

TOLENTINO, Átila Bezerra (Org). Educação patrimonial: reflexões e práticas. João Pessoa: Superintendência do Iphan na Paraíba, 2012.

VLAHAKIS, V. et al. Archeoguide: An Augmented Reality Guide for Archaeological Sites. In: Computer Graphics in Art History and Archaeology, 2002. Disponível em: http://ieeexplore.ieee.org. Acesso em: Dez 2019

WENG, D. et al. Display Systems and Registration Methods for Augmented Reality Applications. In: Optik International Journal for Light and Electron Optics. 2011. Disponível em:

http://www.sciencedirect.com/science/article/pii/. Acesso em: Dez 2019.

ZUFFO, Marcelo Knörich; LOPES, Roseli de Deus. Ambientes de realidade virtual e realidade aumentada na preservação do patrimônio histórico. Disponível em: http://www.arquiamigos.org.br/seminario3d/pdf/zuffo-rvra.pdf. Acesso em: 10 dez. 2019. 